\title{
STUdio Quiz USEd AS A TeST TO COMPREHEND LiSTENING SKILl: Perception of English Education Study Program Student OF TANJUNGPURA UNIVERSITY
}

\author{
Eusabinus Bunau \\ Universitas Tanjungpura, Pontianak, Indonesia \\ E-mail: eusabinus.bunau@fkip.untan.ac.id
}

\begin{abstract}
This article is excerpted from research entitled Comprehending Listening Skill through Quiz. The quiz was administered to students of the English Education Study Program as a semester final test of Listening for Academic Purposes subject. The method of research is quantitative and intended to find out whether or not literature, sport, history, and general knowledge on the quiz was a matter for students to comprehend. The quiz administered to test the students was taken from www.bbclearningenglish.com. The primary data of the research was collected by surveying, and the secondary data was the result of the semester's final test. The survey was implemented by distributing a questionnaire to 43 student respondents attending the test. The technique of data analysis is descriptive. The research found that literature, sport, history, and general knowledge on the quiz were matters to students to comprehend. The matters were varied in accordance with skills characteristics such as the spelling of vocabulary, and the writing of phrase, sentence, and number.
\end{abstract}

Keywords: Quiz; Comprehending; Listening Skill

\section{INTRODUCTION}

By university or higher-level education, the teaching of listening skills is not perceived as an introduction any longer. It is developed higher, for instance, in terms of its learning and testing material. That higher development is intended to fulfill particular standards or criteria of teaching and learning as demanded by the curriculum. The better the university or higher education institution based on accreditation-including its department or study program, the higher standard or criteria demanded by the curriculum.

Although English is taught as a foreign language in Indonesia, its teaching and testing material is served and administered like a native. The teaching and testing material is simply designed or selected by taking from various sources. Native as specific terminology used for this research refers to as it is pronounced, taught, learned, and tested by Englishman, Australian, or American. Hence, English teaching becomes English natively, while to Indonesian, as a matter of fact, English is a foreign language or English as Foreign Language (yourdictionary.com/quiz-program). Moreover, simply taking its teaching, learning, and testing material that is English native is perceived practical since making its material for EFL that is like a native, should fulfill some standardized requirements and conditions.
English as EFL in Indonesia is the only status, but its teaching, learning, and testing are English as native. Thus, taking materials from any available sources is no big deal as far as they have been proven valid, standard, and reliable. So, it's teaching, learning, and testing, to some extent, will approach real English, that is English native. Teaching English native to students learning English as EFL, for instance Listening for Academic Purposes subject, will familiarize students with sounds, spelling, number, pronunciation, structure, and culture of English. The aim is clear, that is to achieve determined instructional objectives. The process of familiarization will eventually urge EFL students to learn English to test as no big deal issue. One of the tests raised as the focus of this research is the Semester Final Test of Listening for Academic Purposes Subject arranged and implemented through the quiz. The test using the quiz was administered under the English Education Study Program of Faculty of Teacher Training and Education, Tanjungpura University.

By analyzing the Semester Final Test result that is not satisfactory, it is assumed that the students had faced difficulties in answering the quiz applied as a test. The assumption is in general at the difficulties that are based on the quiz consisting of spelling, number, phrase, and sentence structure applied in literature, sport, and general knowledge. Confirmation to ensure and clarify the correct answer of the quiz question was given by quiz host or announcer. The quiz 
was administered at the radio station studio as its setting. So, quiz in this research is a test of knowledge, especially as a competition between individuals or teams as a form of entertainment (en.oxforddictionaries.com/definition/quiz, 2019), and a radio or television program in which a group of people compete in answering questions (yourdictionary.com/quiz-program, 2019). The source of the quiz taken as Semester Final Test is (bbclearningenglish.com, 2015). Moreover, the type of quiz question is 9 wh-questions. It means that the type of question requiring the answer as it is questioned. So, the answer is not yes/no answer. The 9whquestions is commonly known as question words comprising what, when, where, why, who, whom, whose, which, and how.

The research is important to carry out for the students' results of the Semester Final Test that was not satisfactory although the process of teaching and learning of Listening for Academic Purposes Subject is perceived proper. Confirmation or clarification on the answer of quiz answer is stated during and after quiz ongoing, or as quiz contestant finished answering. The confirmation or clarification is understandable, but as an assumption, students' mastery of the tested quiz questions on literature, sport, and general knowledge is questionable in terms of spelling, pronunciation, number, and structure of phrase and sentence. This research is important to further prove the assumption by surveying the mastery applied through the questionnaire. Confirmation or clarification made by the quiz host or announcer is also included to ask through the survey.

Based on the assumption, the objective of this research is set to know whether or not spelling, number, and structure of phrase and sentence on the issue of literature, sport, and general knowledge on the quiz matter to students. To add, the objective also includes the description of the matters.

The scope of this research is quiz items taken as Semester Final Test questions for Listening for Academic Purposes Subject. The quiz for this research is quiz as a competition for quiz contestants competed in a radio station or studio as its setting. Furthermore, the value of the Semester Final Test component is $40 \%$ of $100 \%$. Other components consisting of Attendance (10\%), Structural Assignment (20\%), and Mid Semester tests $(30 \%)$ are not part of this research to study. Therefore, the scope of this research only covers students' answers for quiz items taken as Semester Final Test questions. Hence, the analysis of students' difficulties is only focused on spelling, number, and structure of phrase and sentence on the issue of literature, sport, and general knowledge competed or contested in the quiz.

The quiz is a question, item, or short test. An example of a quiz is a series of ten multiple-choice questions for students to answer. To quiz means to test knowledge. An example of to quiz is to ask students to name all the presidents' last names in order (en.oxforddictionaries.com/definition/quiz, 2019). Moreover, besides a short test, a quiz is also a form of sport or game used by the player or gamer to try to answer the items correctly. It is a game to test your knowledge about a certain subject. On the website (yourdictioanry.com/quiz, 2018), it is mentioned that in some countries, a quiz is even also as a brief assessment used in education and similar fields to measure growth in knowledge, abilities, and/or skills. Moreover, the quiz in this research is items to test knowledge on a subject and is intended as a test or exam. The quiz is the one taken and adapted by selecting and eliminating segments in the quiz to be items for the Listening for Academic Purposes Subject.

Furthermore, Vargas (2015) said that selecting teaching listening material and creating a good hand-out takes a long time. Therefore, through an article entitled Listening Cloze Meets Info-Gap: A Hybrid Activity to Exploit Listening Materials, he created effective and cheap material for examination to integrate as many as language skills. Moreover, Vargas (2015) said that it is therefore evident that skills integration is something natural and desirable in the language classroom, and if we are to train competent speakers of English as a second or foreign language, we should incorporate that authenticity in our lessons.

The authenticity of questions or items in the quiz used as Semester Final Test examination studied in this research might have been the factor faced by the students to ideally answer. Flowerdew \& Miller (2005) said that approach used in foreign language listening is communicative, and based on its nature, the material of teaching is conversational. Pedagogically, learning foreign language listening should have a cross-cultural, contextual, and critical dimension. Questions of the quiz in the form of audiotape or audiocassette used as Semester Final Test exam has fulfilled those criteria.

Listening comprehension refers to understanding implied and written phrases and sentences of a language spoken. Comprehending listening, as retrieved from listening comprehension website (Listening Comprehension, 2018), is influenced by skills characteristic of Syntax-word order; sentence structure, Grammar-the rules of language, Morphology-the meaning units in words, Pragmatics/social language-use of language in social contexts, Semanticsknowledge of vocabulary; meaning-based language, and Phonology-use of sounds to encode the meaning of language. Other skills required by the student as an active listener is hearing concentration, memory, and actual perception and comprehension. Without them, a student will struggle hard to understand and memorize what is heard. So, the student will face difficulty to follow the instruction delivered orally or through material delivered in the language laboratory. That oral instruction will determine the success of learning in the classroom or language laboratory.

Listening as an English language skill has its difficulties. The difficulty, for instance, is to understand the structure of phrases influenced by the pronunciation of native English that is hard to listen to. The difficulty is caused by the merger of final and initial syllables of first and second words commonly known as the connected-speech of a phrase (Bunau, 2012). In linguistics context, this connected-speech is also known as phonological rules or the sound patterns of language(Denham \& Lobeck, 2010). It rules syllable of words, words, phrases, and sentences realization of pronunciation in spoken English. The type of phonological rules comprises assimilation, dissimilation, insertion, deletion, fronting, exchange, multiple processes, suprasegmental, stress, and intonation (Denham \& Lobeck, 2010). The merger of the pronunciation is apparent in 
past or participle regular verbs ended with $-d$ or -ed followed by a preposition. For example, phrasal verb turned out in sentence it turned out differently (Bunau, 2012) is pronounced [turn daut], not [turn aut], or locked up abroad, one program on a TV channel that is pronounced [lok dap a brod], not [lokap a brod]. Besides connected-speech pronunciation, dialect also becomes its difficulty, as found in some that are pronounced [som] for British, and [sam] for American.

Schmidt (2016) said that one of the most difficult skills in the language is listening. Through an article entitled Listening Journal for Extensive and Intensive Listening Practice, Schmidt (2016) moreover suggested that there should be a strong need and will to learn listening subject. The main obstacle to listening skills is the incompetence to draw word boundaries. This incompetence has been a particular difficulty for students to answer the Semester Final Test items constructed in the form of a quiz. Mistakes at spelling or writing phrase and sentence that is too diverting from what is meant by the items were the evidence of the incompetence.

To test English Semester Final Test items to Indonesian EFL students is similar to testing German as a foreign language to Dutch students. They will face similarities in terms of difficulty. Although German is taught both inductively and deductively as studied by TammengaHelmantel et al. (2016), still the problem is the incompetence to draw word boundaries.

\section{Methodology}

The method of this research is quantitative, and the type of research is the survey research design. Survey research is a procedure in quantitative research in which investigators administer a survey to a sample using questionnaires or interviews (Creswell, 2012).

This research surveys the students' respondents to collect their opinion on quiz used for the Semester Final Test. The survey comprises a Cross-Sectional Survey Designs and Longitudinal Survey Design (Creswell, 2012). For this research, it is Cross-Sectional Survey Designs. The objective is to measure attitudes and practices, community needs, program evaluation. Hence, this survey research is aimed to describe students' opinions about the difficulties they faced when answering questions of the Semester Final Test constructed in the form of a quiz. Besides, this research is an evaluation of the result of the Semester Final Test and analysis of the difficulties. The analysis is made on the segment and the answer to the questions of the quiz.

This survey research is reasonable to conduct since the result of the Semester Final Test influencing the total score of a subject. The components to determine the pass of a subject is the combination of attendance or activity, structural assignment, mid-semester test, and Semester Final Test. The portion of the components in respect is $10 \%, 20 \%, 30 \%$, and $40 \%$, and making them $100 \%$ in total.

The data of this research is primary and secondary. The technique to collect primary data surveys. The survey, according to Kowalczyk (2018), is a brief interview or discussion with individuals about a specific topic. The term survey is often used to mean collect information.
The survey is to collect opinions on the items or questions for Semester Final Test taken from the quiz and the answers of the quiz. The tool of data collection is a questionnaire containing a series of questions to collect information from research respondents. Creswell (2012) said that questionnaire also means a form used in the survey in which the respondent answers and returns the questionnaire to the researcher. The type of question in the questionnaire is an open question and closed-ended question (Creswell, 2012), and this research applies the closed-ended question.

The research was conducted at the campus of Teacher Training and Education Faculty of Tanjungpura University. The respondent is determined by sampling. Sampling, according to Creswell (2012) is the group of participants in a study selected from the target population from which the researcher generalizes the target population.

The sample is a cluster (Lewin, 2005), consisting of thirdsemester students of class $\mathrm{A}$ and $\mathrm{C}$ taking Listening for Academic Purposes subject in the academic year 2017/2018. The total sample of this research is 43 students. Quantitative and qualitative data of this research is described descriptively (Saldana, 2014).

TABLE I

ANSWER KEY OF THE QUIZ AND SCORING RUBRIC

\begin{tabular}{|c|c|c|c|}
\hline No & Answer Key & $\begin{array}{l}\text { Score } \\
\text { (point) }\end{array}$ & $\begin{array}{c}\text { CS } \\
(40 \%)\end{array}$ \\
\hline 1 & Harry Potter & 5 & 2 \\
\hline 2 & $\begin{array}{l}\text { Harry Potter and the Deathly } \\
\text { Hallows }\end{array}$ & 5 & 2 \\
\hline 3 & Cricket & 5 & 0 \\
\hline 4 & Kate Moss & 5 & 2 \\
\hline 5 & They were fired into space & 5 & 2 \\
\hline 6 & The Terracotta Warriors & 5 & 2 \\
\hline 7 & Spice Girls & 5 & 2 \\
\hline 8 & Sporty, Baby, Scary, Posh, Ginger & 5 & 2 \\
\hline 9 & Vancouver & 5 & 0 \\
\hline 10 & Using fingerprint to pay & 5 & 2 \\
\hline 11 & South Africa & 5 & 0 \\
\hline 12 & m-w-a-h & 5 & 0 \\
\hline 13 & it's not my cup of tea & 5 & 2 \\
\hline 14 & 1814 & 5 & 0 \\
\hline 15 & 366 & 5 & 0 \\
\hline 16 & It's divisible by 4 & 5 & 2 \\
\hline 17 & Propose marriage & 5 & 2 \\
\hline 18 & Diamond & 5 & 0 \\
\hline 19 & USA Los Angeles & 5 & 0 \\
\hline 20 & Hamlet & 5 & 0 \\
\hline & Total score point & 100 & \\
\hline
\end{tabular}

The secondary data of this research is students' Semester Final Test results. The total score of the Semester Final Test is 2878 , and it is mean is 66.93, and is categorized, as suggested by Harris (1996), 'average to good'. The questions for the Semester Final Test are created in the form of a quiz downloaded from (bbclearningenglish.com, 2015). Nevertheless, not all of the quiz downloaded was taken for Semester Final Test questions or items. The teacher of the subject re-arranged by sorting the segments and questions of the quiz. In another word, some parts of the quiz are skipped The segments of the quiz taken for Semester Final Test 
questions cover literature, sport, history, and general knowledge.

Students' answer is scored using a scoring rubric. The rubric also accommodates Consolation Score (CS) to appreciate students' attempts to answer. The CS is only applied to particular considered-difficult writings of spelling, pronoun, phrase, and sentence. The CS is awarded 2 points or $40 \%$ of 5 points. Table I is the Answer Key of the Quiz and Scoring Rubric used to score students' answers.

\section{RESULTS AND DISCUSSION}

The method applied to analyze the data is qualitative (Flick, 2007). It means that the perception of students is described qualitatively from the result of the questionnaire. The Students' Perception whether the answer to the question used as the Final Semester Test was No Matter or Matter is laid out in Fig. 1.

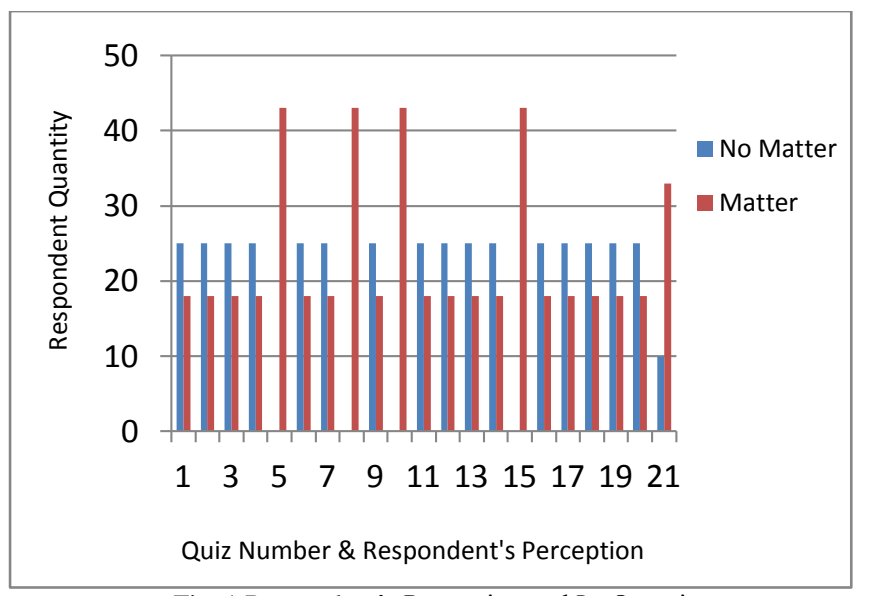

Fig. 1 Respondent's Perception and Its Quantity

The Fig. 1 shows that 25 respondents $(58.14 \%)$ perceiving that the answer of quiz question number 1-5 was no matter, and another 18 respondents $(41.86 \%)$ said that the answer was a matter to them, and 43 respondents $(100 \%)$ claimed that the answer of quiz number 5 was the matter. The answer to the question shows that literature as the content of the quiz has been difficult to comprehend listening. The mistake of the spelling of the answer to question number 1 indicates that respondents have ever seen the novel 'Harry Potter' in the shop window, but they could not memorize the correct spelling of the novel title.

Options for the correct answer were actually mentioned by quiz contestants in the material played for the Semester Final Test, but the students' respondents did not really listen to the confirmation, and therefore, the answer is wrong. Still, the problem for the answer to question number 2 is the spelling found in the title of the novel 'Harry Potter and the Deathly Hallows'.

Question of quiz number 3 deals with the sport. 'Cricket' is a sport. Many $25(58.14 \%)$ respondents claimed that they knew the answer of the quiz although they made mistakes in terms of spelling, and another $18(41.86 \%)$ stated they had no idea with this type of sport.
Statistic of perception for question number 4 is similar to perception for question number 3. The mistake is at the spelling of personal pronoun, 'Kate Moss', a famous model in the fashion industry.

'They were fired into space' is the answer to question number 5 of the quiz. No respondents claimed that they knew the answer to the quiz. The answer needs accuracy because 'they' as reference referred to 'ashes' that is plural, and 'fired' is verb-3 indicating passive sentence initiated with to be 'were'. Verb 'fired' morphologically has a different meaning according to context. In general, the difficulty happens in terms of sentence structure. Difficult vocabulary to guess in the question that leads to the wrong answer is 'cast' that is synonymous to 'player', 'actress', or 'actor'.

Fig. 1 also shows that amount of $25(58.14 \%)$ respondents answered the questionnaire by claiming that they knew the answer to quiz numbers 6, 7, and 9. In other words, the answer is no matter to the respondents. Another 18 (41.86\%) stated that they did not know the answer to the quiz. Moreover, the total respondent of $43(100 \%)$ stated that they did not know the answer to the quiz number 8 and 10 .

The answer to quiz number 6 is 'The Terracotta Warriors'. It is a story of a warrior that invaded London. The respondents made mistakes in terms of spelling and sentence structure. In addition, less prior knowledge of the story had led the students to mistake. 'Spice Girls' is the answer to quiz number 7. It is a famous girl band. The mistake was commonly at the spelling and word choice. 'Girls' indicate plurality, and the confusing word choice students wrote is 'spice', 'space', and 'spike'. The confusion deals with minimal pair as found in phonology (Denham \& Lobeck, 2010, p. 101). Quiz number 8 has a close relation to quiz number 7. 'Sporty', 'Baby', 'Scary', 'Posh', and 'Ginger' are the nicknames of the Spice Girls. Besides the difficulty in terms of spelling, the mistake made was also caused by insufficient prior knowledge on the Spice Girls. 'Posh' is a nickname mostly written incorrectly in terms of spelling.

Question number 9 of the quiz is still on the Spice Girls. The answer to the quiz is 'Vancouver', the town where they performed their show for the first time. Prior knowledge on the name of world cities or towns that is insufficient has also led the answer into a mistake. Question number 10 of the quiz is about the mode of payment in German. The answer is 'using a fingerprint to pay'. The difficulty is at sentence structure, and the most are that the students have never really heard about that. It has a connection with currently most spoken payment mode like e-money, PayPal, t-cash, fin-tech, and block-chain, that is in general meaning to pay or to do a transaction using Applications (Apps) managed by the independent corporation. The use of fingerprint is more or less similar to the Personal Identification Number (Topping, 1990) to authorize the transaction.

The perception of question number $11-15$ of the quiz in Fig. 1 above indicates that $25(58.14 \%)$ of the students claimed that they could answer the quiz, or that the quiz is no matter, and another $18(41.86 \%)$ stated they could not. The answer to quiz number 11 is 'Rugby', a type of sport. This type of sport, like Cricket, is very famous in commonwealth countries, but 
not common to EFL students. Although most of the respondents claimed that they could answer the quiz, the mistake is mostly at the spelling of 'South Africa'.

The question of the quiz number 12 is on giving air kiss a noise, a word. The question is how to write that air kiss. The answer is 'mwah' ( $\mathrm{m}-\mathrm{w}-\mathrm{a}-\mathrm{h})$. The mistake on spelling made by the respondents shows that the students still have problems with the English alphabet and spelling. Spelling is how phoneme is phonologically sounded or aspirated (Denham \& Lobeck, 2010).

The question for number 13 is 'In English, if there's something we don't like very much, for example a sport or a type of music, we can say...'. The answer is 'It's not my cup of tea'. The difficulty is still on sentence structure, incomplete sentences. The ' $\mathbf{s}$ is to be, not possessive. The apostrophe in 'it's' may refer to 'it is', 'it was', 'it has', depending on the tense of the sentence.

Quiz number 14 requires a number as the answer. The answer is 1814 . The mistake in writing the number indicates that the knowledge on number saying in English is still insufficient, for instance, is, to differ sound [ti] and [tin] in 'fourteen' and 'forty'.

Question number 15 is about leap year that is divisible by four. The answer is 366 is divisible by four. Although the answer seems easy $18(41.86 \%)$ respondents claimed that they did not know the answer, or that the answer was the matter. It indicates that the knowledge on numbers, both ordinal and cardinal (Denham \& Lobeck, 2010), is still insufficient.

Fig. 1 furthermore shows that the total respondent claimed they did not know the answer to quiz number 16 . Meanwhile, an amount of $25(58.14 \%)$ respondents stated they knew the answer although spelling and/or writing is incorrect for question number $17-20$ of the quiz. The rest, that is 18 $(41.86 \%)$ admitted they did not know the answer, or that the answer still matters to them.

The answer to quiz number 16 is 'It's divisible by 4'. Some students' respondents wrote divided by. 'Divided' is synonymous to 'divisible', but the word requested is divisible, and so is the subject of the sentence applying apostrophe ' $S$ indicating It is, not Its that is possessive.

The answer to quiz number 17 is '(Women can) Propose marriage'. 'Woman can' in bracket is optional. Still, as previously mentioned, the mistake is on spelling, and firstly is on the phrase or sentence structure (Denham \& Lobeck, 2010). Although the question of the quiz was led with the clue, that is modal 'can', but the students wrote the verb 'married' that is third form or adjective. It requires 'marriage' that is a noun. This mistake indicates that it is problematic for students to morphologically distinguish the part of speech, or word class, or word type(Denham \& Lobeck, 2010).

The question number 18 of the quiz is 'This month is the 75 Anniversary of the BBC World Service. What precious material is associated with a 75th Anniversary?' The answer is 'Diamond'. Other precious material with a similar association is 'silver' for the 25 th anniversary and 'gold' for the 50th anniversary.

The question of the quiz for number 19 is 'The World Service began as the BBC Empire Service in 1932. Which country hosted the Olympics that year?', and the answer is 'USA (Los Angeles)'. 'Los Angeles' in bracket is optional. Based on the questionnaire, it was found out that many 25 (58.14\%) students respondents claimed they knew the answer although some of them still made mistakes in terms of spelling for naming the city of 'Los Angeles'. For not listening, perhaps, the amount of $18(41.86 \%)$ of the students respondents claimed they did not know the answer to question number 19 of the quiz.

Question number 20 of the quiz is on the Shakespearean character speaking the famous soliloquy which begins "To be or not to be". The answer is 'Hamlet'. Based on the questionnaire tabulated, it is found out that $25(58.14 \%)$ students respondents claimed they knew the answer to the question, and another 18 (41.86\%) stated they did not know its answer.

Finally, question number 21 is about students' consciousness of confirmation provided by contestants of the quiz as well as the host or announcer of the quiz. The confirmation is provided for each question asked during the quiz. Total respondents, that is $33(76.74 \%)$ claimed that they did not realize that confirmation to heading to the correct answer was provided.

Confirmation for each answer of the quiz was given, directly by repeating the correct answer or by inserting the correct answer into dialogue or discussion between host and contestant of the quiz. Besides confirmation, the question or item of the quiz was also arranged with purpose as a clue. More than ever, the duration provided to study the questions before the audiotape played was sufficient enough.

The implication of the research and practice of this article is language characteristic skills mastery. The answers of the quiz such as 'they were fired into space', 'using a fingerprint to pay', 'it's not my cup of tea', 'it's divisible by 4', and 'propose marriage' are examples categorized into skills characteristics of Syntax-word order, Sentence structure, Grammar-the rules of language, and Phonology-use of sounds to encode the meaning of language. To extend, 'it's divisible by 4', and 'propose marriage' are also included in skill characteristics of Morphology-the meaning units in words.

Furthermore, the answers of the quiz like Harry Potter, cricket, spice girls, diamond, Vancouver, Hamlet, Kate Moss, Sporty, Baby, Scary, Posh, Ginger, $m-w-a-h$, USA (Los Angeles), 1814 and 366 are the examples categorized into skill characteristics of Morphology-the meaning units in words, Pragmatics or social language-use of language in social contexts, Semantics-knowledge of vocabulary; meaningbased language, and Phonology-use of sounds to encode the meaning of language.

\section{CONCLUSIONS}

Based on data analysis done towards the results of the questionnaire and its discussion, it can be concluded that spelling, the structure of phrase and/or sentence, and number are peculiar difficulties to students to comprehending. The material comprehended includes literature, sport, history, and general knowledge questioned in the quiz. 
The difficulties vary based on the characteristic of skills like Syntax-word order; sentence structure, Grammar-the rules of language, Morphology-the meaning units in words, Pragmatics; social language-use of language in social contexts, Semantics-knowledge of vocabulary; meaningbased language, and Phonology-use of sounds to encode the meaning of language.

The category of the mean score of students' Semester Final Test is classically 'average to good', indicating that listening comprehension of Listening for Academic Purposes Subject through quiz is not bad for EFL students. The quiz, as mentioned earlier, is a question, or brief test or exam. Besides, the quiz is brain sport, a game played to answer correctly.

The mastery of language characteristic skills that are still lacking as implicated through this article should be strengthened in daily English teaching to EFL students to have better practice in the future. Moreover, to make listening comprehension maximized, it is kindly suggested to teachers and lecturers of listening subject to frequently using the quiz as teaching material as well as material for examination. It is also kindly suggested to students and pupils to frequently exercising listening quiz material, mainly the one comes from a valid and reliable source like (bbclerningenglish.com), and other related sources.

The result of this research shows that characteristics of the English skills found available in the quiz designed as tests have been mattered to students to comprehend. Therefore, suitable future research should be focused more on characteristic skills and language features found and used in teaching both productive and receptive English skills.

\section{ACKNOWLEDGMENT}

I would like to thank the Dean of Teacher Training and Education Faculty of Tanjungpura University for securing Non-Budgeter Fund Fiscal Year 2018 to finance the research resulting in this article, and anonymous reviewers for making this article available in this journal.

\section{REFERENCES}

bbclearningenglish.com. (2015)

Bunau, E. (2012). Kesulitan Mentranskripsi Teks pada Mata Kuliah Listening Comprehension di Laboratorium Bahasa oleh Mahasiswa Bahasa Inggris Fkip Untan. Jurnal Cakrawala Kependidikan, 7(1), 46-56.

Creswell, J. W. (2012). Educational Research: Planning, Conducting and Evaluating Quantitative and Qualitative Research (4 ed.). Boston: Pearson Education.

Denham, K., \& Lobeck, A. (2010). Linguistics for Everyone: an Introduction. Boston: Wadsworth Cengage Learning.

en.oxforddictionaries.com/definition/quiz. (2019)

Flick, U. (2007). Designing Qualitative Research. Singapore: Sage Publications Ltd.

Flowerdew, J., \& Miller, L. (2005). Second Language Listening: Theory and Practice. New York: Cambridge University Press.
Harris, D. P. (1996). Testing English as a Second Language. New York: McGraw-Hill.

Kowalczyk, D. (2018). what-is-survey-research-definitionmeth. In D. Kowalczyk (Ed.): https://study.com/.

Lewin, C. (2005). Elementary Quantitative Methods. In B. Somekh \& C. Lewin (Eds.), Research Methods in the Social Sciences (pp. 215-225). London: Sage Publication Ltd.

Listening Comprehension. (2018). https://edie502.wikispaces.com/Listening+Comprehe nsion.

Saldana, J. (2014). Coding and Analysis Strategies. In P. Leavy (Ed.), The Oxford Handbook of Qualitative Research (pp. 581-605). Oxford: Oxford University Press.

Schmidt, A. (2016). Listening Journal for Extensive and Intensive Listening Practice. English Teaching Forum, 54(2), 2-11.

Tammenga-Helmantel, M., Bazhutkina, I., Steringa, S., Hummel, I., \& Suhre, C. (2016). Comparing Inductive and Deductive Grammatical Instruction in Teaching German as a Foreign Language in Dutch Classroom. Journal System, 63, 101-114. doi: https://doi.org/10.1016/j. system.2016.09.002

Topping, D. M. (1990). A Dialect Survey of the Land Dayaks of Sarawak. Language Oral Tradition in Borneo, 2, 247-274.

Vargas, J. P. Z. (2015). Listening Cloze Meets Info-Gap: A Hybrid Activity to Exploit Listening Materials. English Teaching Forum, 53(4), 24-32.

yourdictioanry.com/quiz. (2018)

yourdictionary.com/quiz-program. (2019) 